\title{
CIN85 drives $B$ cell responses by linking BCR signals to the canonical NF-KB pathway
}

\section{Citation}

Kometani, Kohei, Takayuki Yamada, Yoshiteru Sasaki, Tadashi Yokosuka, Takashi Saito, Klaus Rajewsky, Masamichi Ishiai, Masaki Hikida, and Tomohiro Kurosaki. 2011. CIN85 drives B cell responses by linking BCR signals to the canonical NF-kB pathway. The Journal of Experimental Medicine 208(7): 1447-1457.

\section{Published Version}

doi:10.1084/jem.20102665

\section{Permanent link}

http://nrs.harvard.edu/urn-3:HUL.InstRepos:11189262

\section{Terms of Use}

This article was downloaded from Harvard University's DASH repository, and is made available under the terms and conditions applicable to Other Posted Material, as set forth at http:// nrs.harvard.edu/urn-3:HUL.InstRepos:dash.current.terms-of-use\#LAA

\section{Share Your Story}

The Harvard community has made this article openly available.

Please share how this access benefits you. Submit a story.

\section{Accessibility}




\title{
CIN85 drives $\mathrm{B}$ cell responses by linking $\mathrm{BCR}$ signals to the canonical NF- $\mathrm{KB}$ pathway
}

\author{
Kohei Kometani, ${ }^{1}$ Takayuki Yamada, ${ }^{1,3}$ Yoshiteru Sasaki, ${ }^{4}$ Tadashi Yokosuka, ${ }^{2}$ \\ Takashi Saito, ${ }^{2}$ Klaus Rajewsky, ${ }^{4}$ Masamichi Ishiai, ${ }^{3}$ Masaki Hikida, ${ }^{1,3}$ \\ and Tomohiro Kurosaki ${ }^{1,3,5}$ \\ 1'Laboratory for Lymphocyte Differentiation and 2Laboratory for Cell Signaling, RIKEN Research Center for Allergy
and Immunology, Turumi-ku, Kanagawa 230-0045, Japan
3Department of Molecular Genetics, Institute for Liver Research, Kansai Medical University, Fumizono-cho 10-15,
Osaka 570-8506, Japan
4Program in Molecular and Cellular Medicine, Children's Hospital, and Immune Disease Institute, Harvard Medical School,
Boston, MA 02115
5Laboratory of Lymphocyte Differentiation, WPI Immunology Frontier Research Center, Osaka University, Suita, Osaka 565-0871, Japan
}

CIN85, an adaptor protein which binds the C-terminal domain of tyrosine phosphorylated $\mathrm{Cbl}$ and $\mathrm{Cbl}-\mathrm{b}$, has been thought to be involved in the internalization and subsequent degradation of receptors. However, its physiological function remains unclear. To determine its role in B cells, we used $\mathrm{Mb1-cre} \mathrm{to} \mathrm{generate} \mathrm{mice} \mathrm{with} \mathrm{a} \mathrm{B} \mathrm{cell-specific} \mathrm{deletion} \mathrm{of}$ CIN85. These mice had impaired T cell-independent type II antibody responses in vivo and diminished IKK- $\beta$ activation and cellular responses to $B$ cell receptor (BCR) cross-linking in vitro. Introduction of a constitutively active IKK- $\beta$ construct corrected the defective antibody responses as well as cellular responses in the mutant mice. Together, our results suggest that CIN85 links the BCR to IKK- $\beta$ activation, thereby contributing to T cellindependent immune responses.

\section{CORRESPONDENCE}

Tomohiro Kurosaki:

kurosaki@rcai.riken.jp

Abbreviations used: APC, allophycocyanin; CGG, chicken $\gamma$ globulin; FO, follicular; GC, germinal center; GST, glutathione $S$-transferase; MZ, marginal zone; NIP, (4-hydroxy-5indo-3-nitrophenyl)acetyl; NP, 4-hydroxy-3-nitrophenylacetyl; SH3, Src homology 3; TD, T cell-dependent; TI-II, T cellindependent type II; UBD, ubiquitin-binding domain.
By recruiting signaling proteins into complexes, adaptor molecules create nodes of regulation and activity. CD2AP (alternatively named CMS), the founding member of the CD2AP/ CIN85 family of adaptor proteins, was initially isolated in a yeast interaction screen as a binding partner of CD2 expressed on T cells (Dustin et al., 1998). Subsequently, its mammalian homologue CIN85 (Cbl interacting protein of $85 \mathrm{kD}$ ) was identified as a partner of the E3 ubiquitin ligase Cbl (Take et al., 2000). CIN85 contains three Src homology 3 (SH3) domains at the $\mathrm{N}$ terminus that recognize an atypical proline-arginine motif (PX(P/A)XXR), a central proline-rich region acting as an interaction module for other SH3 domain-containing proteins, and a coiled-coil domain in the $\mathrm{C}$ terminus

Yoshiteru Sasaki's present address is Laboratory for Stem Cell Biology, RIKEN Center for Developmental Biology, Kobe 650-0047, Japan.

Masamichi Ishiai's present address is Laboratory of DNA Damage Signaling, Dept. of Late Effect Studies, Radiation Biology Center, Kyoto University, Sakyo-ku, Kyoto 606-8501, Japan.

Masaki Hikida's present address is Center for Innovation in Immunoregulative Technology and Therapeutics, Graduate School of Medicine, Kyoto University, Sakyo-ku, Kyoto 606-8501, Japan.
(Dikic, 2002; Fig. 1 A). CIN85 is expressed in almost all the tissues, where at least 10 different isoforms are differentially expressed in each tissue (Gout et al., 2000; Take et al., 2000). For instance, extra long and long isoforms (CIN85-xl, and CIN85-1) are expressed abundantly in nerve systems, whereas in immune systems CIN85-1 and CIN85- $\Delta \mathrm{A}$ isoforms are expressed dominantly (Fig. 1 C; Shimokawa et al., 2010).

Based on coimmunoprecipitation experiments, colocalization studies, and in vitro proteinprotein interaction assays using fibroblasts, it has been proposed that CIN85 primarily functions in endocytosis to down-regulate receptor tyrosine kinase activity (Dikic and Giordano, 2003). According to this model, CIN85 constitutively associates with endophilin and, on stimulation with growth factors such as epidermal growth factor, complexes with $\mathrm{Cbl}$ to mediate receptor down-regulation (Petrelli et al., 2002; Soubeyran et al., 2002). The same mechanism

\footnotetext{
2011 Kometani et al. This article is distributed under the terms of an Attribution-Noncommercial-Share Alike-No Mirror Sites license for the first six Attribution-Noncommercial-Share Alike-No Mirror Sites license for the first six
months after the publication date (see http://www.rupress.org/terms). After six months it is available under a Creative Commons License (Attribution-Noncommercial-Share Alike 3.0 Unported license, as described at http://creativecommons org/licenses/by-nc-sa/3.0/).
} 


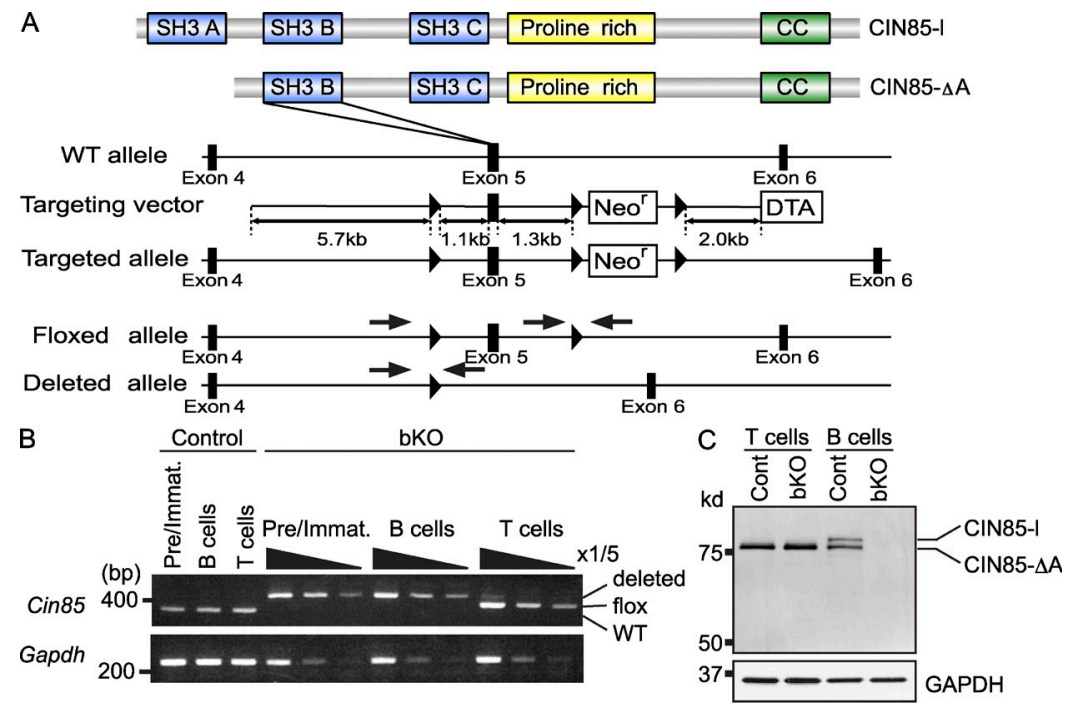

Figure 1. Generation of CIN85 bKO mice. (A) CIN85-I and CIN85- $\triangle$ A contain three or two SH3 domains, respectively. Both isoforms contain a prolinerich region and a coiled-coil (CC) domain. A schematic of CIN85 WT and floxed allele is shown. Exon 5 is flanked by two loxP sites. Arrows indicate primer position for PCR. (B) BM pre-B cells and immature B cells (Pre/Immat.) or spleen $B$ cells or T cells from mb1-Cre; CIN85 ${ }^{\mathrm{wt} / \mathrm{Y}}$ (control) or mb1-Cre; CIN85 f/Y (CIN85 bKO) mice were sorted. CIN85 is located on the $X$ chromosome and $Y$ indicates $Y$ chromosome. DNA was extracted from sorted cells and the deletion efficiency was assayed by PCR. The template DNA was serially diluted. (C) Inactivation of the CIN85 was confirmed by Western blotting in spleen B cells and $T$ cells. Migration of molecular mass markers is shown on the left side. The membrane was stripped and reprobed with anti-GAPDH antibody. Representative data of three independent experiments are shown. also appears to operate in immune cells. CIN85 overexpression in the RBL-2H3 rat mast cell line accelerated the redistribution of engaged FceRI complexes, their sorting in early endosomes, and their delivery to a lysosomal compartment for degradation (Molfetta et al., 2005). Consequently, FceRImediated degranulation was impaired. In addition to affecting endocytosis, overexpression of CIN85 in the RBL-2H3 was also reported to decrease the protein level of Syk, an effect presumably mediated through Cbl (Peruzzi et al., 2007). Overall, these data indicate that CIN85 plays a negative role in the context of FceRI signaling, consistent with the model established in fibroblasts.

In contrast to the mast cell line data, a positive role for CIN85 in pre-TCR signaling has been recently suggested. The cytoplasmic tail of pre-TCR- $\alpha$ possesses a poly-proline-arginine sequence that interacts in vitro with $\mathrm{SH} 3$ domains of CD2AP, as well as CIN85, and deletion of the pre-TCR- $\alpha$ CD2AP/ CIN85-binding motif impaired pre-TCR-mediated calcium mobilization in Jurkat $\mathrm{T}$ cells (Navarro et al., 2007). Because both CD2AP and CIN85 are recruited to the cytoplasmic domain of the pre-TCR- $\alpha$ chain, it is likely that both CIN85 and CD2AP act downstream of the pre-TCR to promote pre-TCR signaling. Thus, collectively with its functions in mast cells, CIN85 may mediate distinct biological outcomes that depend on the cell types and developmental stages of each cell type.

To test the physiological function of CIN85 in B lineage cells, we have generated B cell-specific CIN85 knockout mice. In this paper, we report that CIN85 links the BCR to IKK- $\beta / N F-\kappa B$ activation, thereby contributing to $T$ cellindependent immune responses.

\section{RESULTS}

\section{Expression of CIN85 in B lineage cells}

During a yeast two-hybrid screen for BLNK (alternatively named SLP-65 or BASH) interacting proteins, we found that one of the clones isolated encoded CIN85. Using a reverse strategy with CIN85 as a bait, Watanabe et al. (2000) had previously identified BLNK as a CIN85 interacting protein. BLNK is a key adaptor molecule in BCR signaling and subsequent B cell responses (Fu et al., 1998; Goitsuka et al., 1998; Wienands et al., 1998), which prompted us to hypothesize that CIN85 could play a significant role upstream and/or downstream of BLNK in the BCR signaling context. Before addressing this issue, we first examined which CIN85 isoform is expressed in B cells because several isoforms of CIN85, generated by different promoter usage and alternative splicing, had already been reported (Buchman et al., 2002; Shimokawa et al., 2010). Western blotting analysis using an antibody raised against a C-terminal region of CIN85, common to all isoforms, detected two protein species in lysates of splenic B cells (Fig. $1 \mathrm{C}$ ). We concluded that the larger and smaller isoforms represent CIN85-1 and CIN85$\Delta \mathrm{A}$, respectively, because transcripts generating these two isoforms were detected in splenic B cells (Fig. S1 A) and because expression of cDNAs encoding the two isoforms in $293 \mathrm{~T}$ cells gave rise to proteins that co-migrated with the endogenous CIN85 proteins in splenic B cells (Fig. S1 B).

In agreement with the previous data that both CIN85-1 and CIN85- $\Delta \mathrm{A}$ transcripts are expressed in various immune cell lineages, we found their expression not only in B cells but also in macrophages, DCs, and T cells in the spleen. Because B cells can be divided into several subsets based on their developmental stage or location, we examined expression of the two transcripts in each subpopulation. CIN85-1 mRNA was higher in naive follicular (FO) and marginal zone (MZ) B cells in the spleen relative to developing $\mathrm{B}$ cells (pro-/pre-B and immature B cells) in the BM. We also observed significantly lower levels of CIN85-1 and CIN85- $\Delta \mathrm{A}$ transcripts in isolated germinal center (GC) B cells and in splenic B cells activated in vitro with anti-IgM, anti-CD40 antibody, IL-4, or toll-like receptor ligands (Fig. S1 A). CD2AP was also expressed in splenic B cells, as determined by quantitative (q) PCR and Western blotting analysis (Fig. S1, A and C). 
Spleen
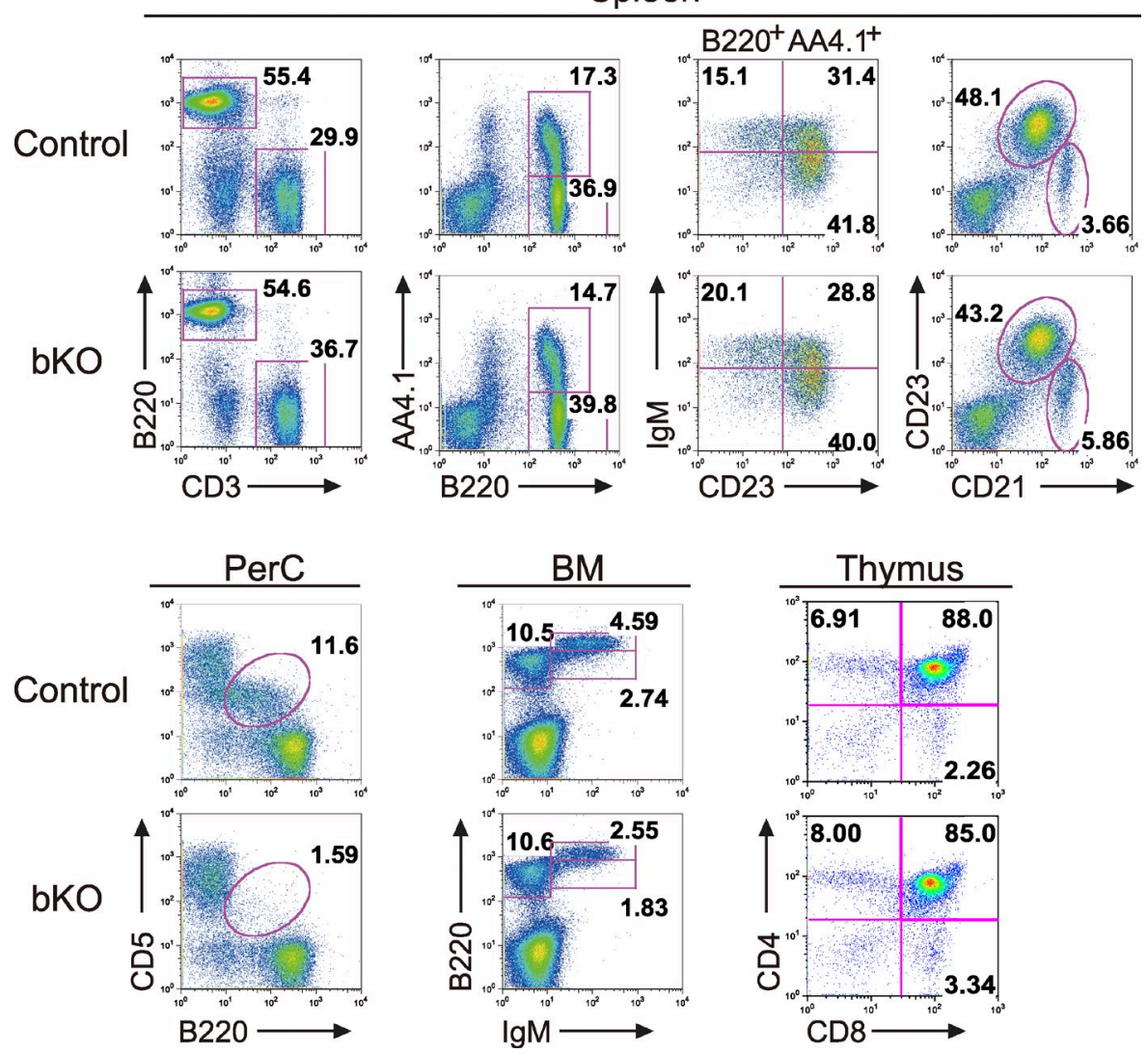

BM

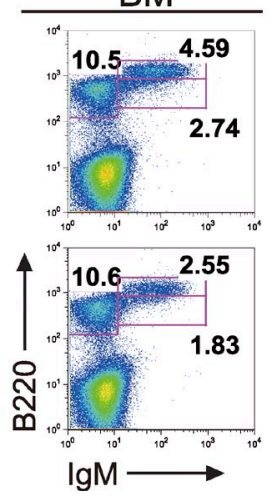

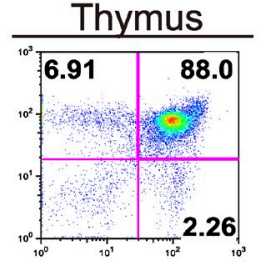

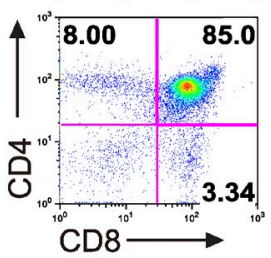

Figure 2. B-1a cells in the peritoneal cavity are reduced in CIN85 bKO mice. $\mathrm{B}$ and $\mathrm{T}$ cell development in the BM, spleen, thymus, and peritoneal cavity ( $\mathrm{PerC}$ ) of control and CIN85 bKO mice were analyzed by flow cytometry. Numbers represent the percentages of cells within the gates. Representative data of seven independent experiments are shown.

study, mb1-cre; CIN85 ${ }^{\mathrm{wt} / \mathrm{Y}}$ mice were used as control mice. It was previously reported that mb1 is transcribed, at least to some extent, in thymic $\mathrm{T}$ cells. Probably because of this, $\sim 1 \%$ of the CIN85 allele in splenic $\mathrm{T}$ cells was deleted; however, this leaky deletion had almost no effect on the total number of splenic $\mathrm{T}$ cells (Table I). Moreover, overall $\mathrm{T}$ cell development in $\mathrm{mb1} 1$-cre; $\mathrm{CIN} 85^{\mathrm{A} / \mathrm{Y}}$ mice was normal, as assessed by expression of CD4 and CD8 of the thymocytes (Fig. 2).

$\mathrm{B}$ cell development in the mutant mice was examined by multiparameter flow cytometry. In the BM of the mb1-cre; CIN85 ${ }^{\mathrm{A} / \mathrm{Y}}$ mice, no gross developmental arrest was observed; however, the total number of

\section{CIN85 is indispensable for B-1a B cell development}

Because CIN85 is expressed in many different immune cells, to examine its B cell-intrinsic functions, we generated B cellspecific knockout mice by crossing the mb1-cre mouse, which has a Cre recombinase transgene under the control of the $m b 1$ promoter (mb1-cre; Hobeika et al., 2006), with a mouse in which Cin85 exon 5 is flanked by loxP sites $\left(\mathrm{CIN} 85^{\mathrm{A} / \mathrm{Y}}\right.$; CIN85 is located on the $\mathrm{X}$ chromosome; Fig. $\left.1 \mathrm{~A}\right)$. Exon 5 encodes an SH3 B region that is present in both CIN85-1 and CIN85- $\Delta$ A isoforms (Fig. $1 \mathrm{~A}$ ). As expected, in these mice (mb1-cre; CIN85/ $5^{\mathrm{A} / \mathrm{Y}}$; shown as CIN85 bKO or $\mathrm{bKO}$ in figure legends or figures, respectively) efficient deletion of the targeted exon was seen in early B cells as well as peripheral splenic B cells (Fig. 1 B). Moreover, there was no detectable CIN85-1 and CIN85- $\Delta$ A protein in $\mathrm{B}$ cell extracts from the spleen of mb1-cre; CIN85 $5^{\mathrm{A} / \mathrm{Y}}$ mice (Fig. 1 C). In this immature and recirculating B cells was reduced by $\sim 30 \%$ (Table I). Reflecting this decrease, the number of $\mathrm{B} 220^{+}$ B cells in the spleen was also reduced by $\sim 20 \%$ (Table I). Peripheral splenic B cells can be divided into immature (transitional [T] 1,T2, and T3), mature FO, and mature MZ B cells, based on the expression of AA4.1, IgM, B220, CD23, and CD21 as described previously (Hardy and Hayakawa, 2001). The numbers of MZ B cells and immature T1 B cells were similar between control and mb1-cre; CIN $85^{\mathrm{A} / \mathrm{Y}}$ mice, whereas the numbers of immature $\mathrm{T} 2$, immature $\mathrm{T} 3$, and mature FO B cells were reduced by $\sim 20 \%$ in the mutant mice. The $\mathrm{B}$ cell subset most affected in the mutant mice was the peritoneal B-1a B cells, which were approximately eightfold reduced. Thus, we conclude that CIN85 is required for normal development or maintenance of the peritoneal B-1a B cell compartment.

Table I. Lymphocyte population in CIN85 bKO mice

\begin{tabular}{|c|c|c|c|c|c|c|c|c|c|c|}
\hline \multirow[t]{2}{*}{ Genotype } & \multicolumn{3}{|c|}{$\mathrm{BM}\left(\times 10^{6}\right)$} & \multicolumn{6}{|c|}{ Spleen $\left(\times 10^{6}\right)$} & \multirow{2}{*}{$\begin{array}{c}\operatorname{PerC}\left(\times 10^{5}\right) \\
\text { B-1a }\end{array}$} \\
\hline & Pro/Pre & Immature & Recirculate & $\mathrm{T} 1$ & T2 & T3 & FO & $\mathrm{MZ}$ & T cells & \\
\hline Control & $8.9 \pm 2.8$ & $3.7 \pm 1.4$ & $3.4 \pm 0.3$ & $1.7 \pm 0.3$ & $3.6 \pm 0.6$ & $3.4 \pm 1.0$ & $24.6 \pm 2.6$ & $2.5 \pm 0.5$ & $21.5 \pm 2.4$ & $3.0 \pm 0.5$ \\
\hline bKO & $8.9 \pm 2.5$ & $2.6 \pm 1.0$ & $2.3 \pm 0.3$ & $1.9 \pm 0.3$ & $2.8 \pm 0.6$ & $2.7 \pm 0.8$ & $19.5 \pm 1.9$ & $2.8 \pm 0.5$ & $19.4 \pm 1.8$ & $0.4 \pm 0.2$ \\
\hline
\end{tabular}

Mean cell numbers of each population were calculated on the basis of total cell number and the percentages obtained from the flow cytometric analysis. Data are shown as mean \pm SE (control, $n=7 ;$ bKO, $n=7$ ). Pro, pro-B cells; Pre, pre-B cells, Immature, immature B cells; Recirculate, recirculating B cells; T1, T1 B cells; T2, T2 B cells; T3, T3 B cells; FO, FO B cells; MZ, MZ B cells; PerC, peritoneal cavity. 

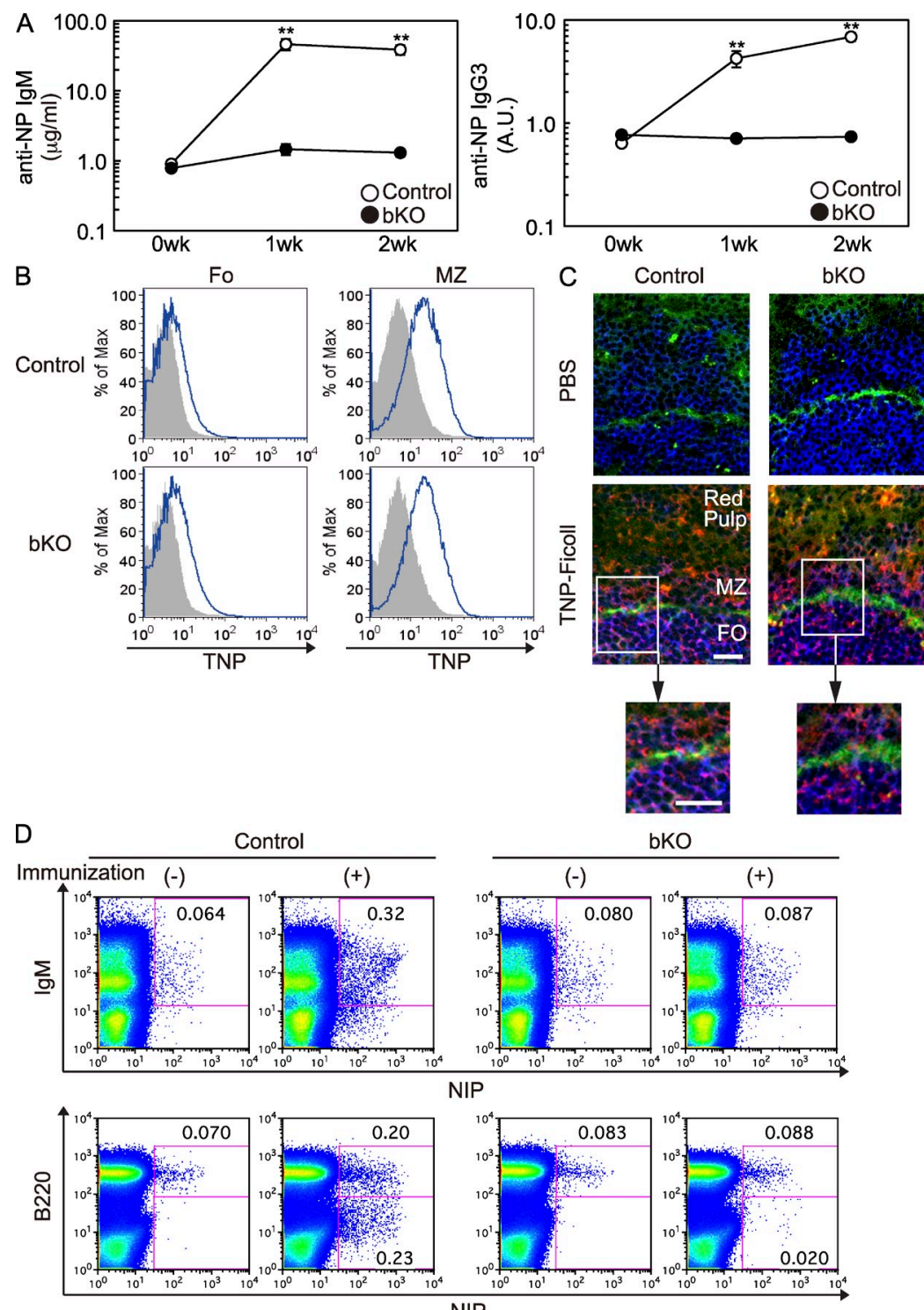

NIP

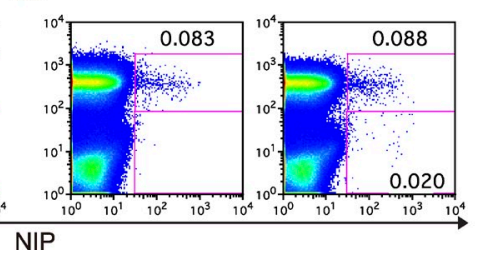

Figure 3. TI-II but not TD responses are impaired in CIN85 bKO mice. (A) Control or CIN85 bKO mice were injected i.p. with $50 \mu \mathrm{g} \mathrm{NP-Ficoll.} \mathrm{Sera} \mathrm{from} \mathrm{each} \mathrm{mouse} \mathrm{were}$ collected before and every week after the immunization and the titers of anti-NP IgM (micrograms per milliliter) and IgG3 (arbitrary units [A.U.]) were measured by ELISA. Results are shown as the mean \pm SD. ${ }^{*}, P<0.01$. Each group consisted of at least four mice and the representative data of three repeated experiments are shown. ( $B$ and $C$ ) Mice were injected i.v. with PBS or $100 \mu \mathrm{g}$ TNP-Ficoll. After $30 \mathrm{~min}$, spleens were collected and TNP-binding B cells were analyzed by flow cytometry (B) or immunohistochemistry (C). In the flow cytometric analysis, FO B cells and MZ B cells were defined as $\mathrm{CD} 21^{\mathrm{lo}} \mathrm{CD} 23^{\text {hi }}$ and $\mathrm{CD} 21^{\text {hi }} \mathrm{CD} 23^{\text {lo }}$ cells, respectively. The gray histogram represents PBS-injected control mice. Frozen sections were stained with antiMAdCAM-1 (green), TNP (red), and B220 (blue) antibodies. Bars, $20 \mu \mathrm{m}$. (D) Spleen cells were collected from control or CIN85 bKO mice $4 \mathrm{~d}$ after the i.p. injection with or without NP-Ficoll and analyzed by flow cytometry. NP-binding B cells were detected by staining with NIP-BSA-PE as described in the Materials and methods. Representative data of at least two independent experiments are shown (B-D).

mechanisms. In vivo, antigen accessibility and its recognition are critical for initiating immune responses and, in this regard, the importance of MZ B cells in inducing TI-II immune responses is well documented (Guinamard et al., 2000). Moreover,

\section{CIN85 is essential for normal T cell-independent immune responses}

To determine whether CIN85 is essential for B cell responses to antigen in vivo, we immunized mice with 4-hydroxy-3nitrophenylacetyl (NP) coupled to chicken $\gamma$ globulin (CGG; NP-CGG) or Ficoll (NP-Ficoll) to elicit T cell-dependent (TD) and T cell-independent type II (TI-II) immune responses, respectively. The NP-specific TD IgM response was somewhat decreased in mb1-cre; CIN85 ${ }^{\mathrm{f} / \mathrm{Y}}$ mice, whereas the IgG1 response was slightly increased. Moreover, the amount of higher affinity anti-NP IgG1, as assessed by using $\mathrm{NP}_{1}$ BSA as a capture antigen in the ELISA assay, was not significantly altered in the mutant mice (Fig. S2 A). GC formation took place normally in the mutant mice (Fig. S2 B).

In contrast, NP-Ficoll responses were barely detectable in mb1-cre; CIN85 ${ }^{\mathrm{A} / \mathrm{Y}}$ mice, both in terms of NP-specific IgM and IgG3 (Fig. 3 A). Having demonstrated the importance of CIN85 in TI-II responses, we wished to address the underlying recent studies have demonstrated that $\mathrm{MZ} B$ cells rapidly capture complement-opsonized antigens, such as Ficoll, and deliver these antigens to the B cell follicles (Cinamon et al., 2008). Thus, one possible explanation for the failure of mb1cre; CIN85 ${ }^{\mathrm{f} / \mathrm{Y}}$ mice to elicit a TI-II response is that, despite the presence of MZ B cells, defined as CD21 hi CD23 lo (Fig. 2), these cells may not be able to capture Ficoll and subsequently transport it. However, our analysis renders this possibility unlikely; MZ B cells in mb1-cre; CIN85 ${ }^{\mathrm{f} / \mathrm{Y}}$ mice bound TNPFicoll and transported it into the FO zones (Fig. 3, B and C).

Next, we analyzed the frequency of NP-specific B cells in the spleen on day 4 after the NP-Ficoll immunization. Before immunization, we found almost equal numbers of NP-reactive precursor B cells at frequencies consistent with previous results (Anderson et al., 2007). The percentage of NP-specific B cells in control mice increased from 0.06 to $0.32 \%$ after immunization, whereas there was only a barely detectable increase in mb1-cre; CIN85 ${ }^{\mathrm{fl} / \mathrm{Y}}$ mice (Fig. 3 D). Thus, CIN85 is most 


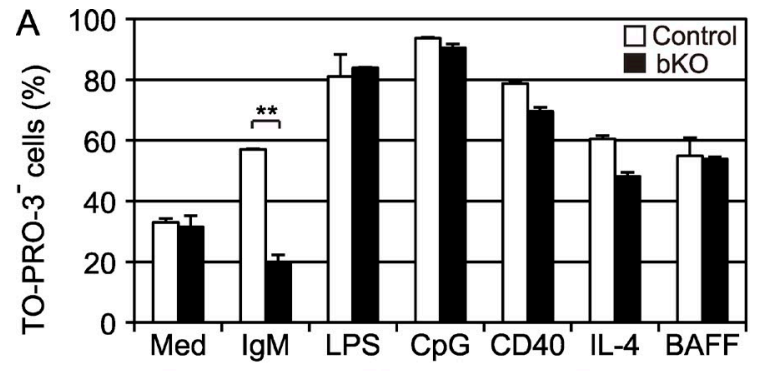

B
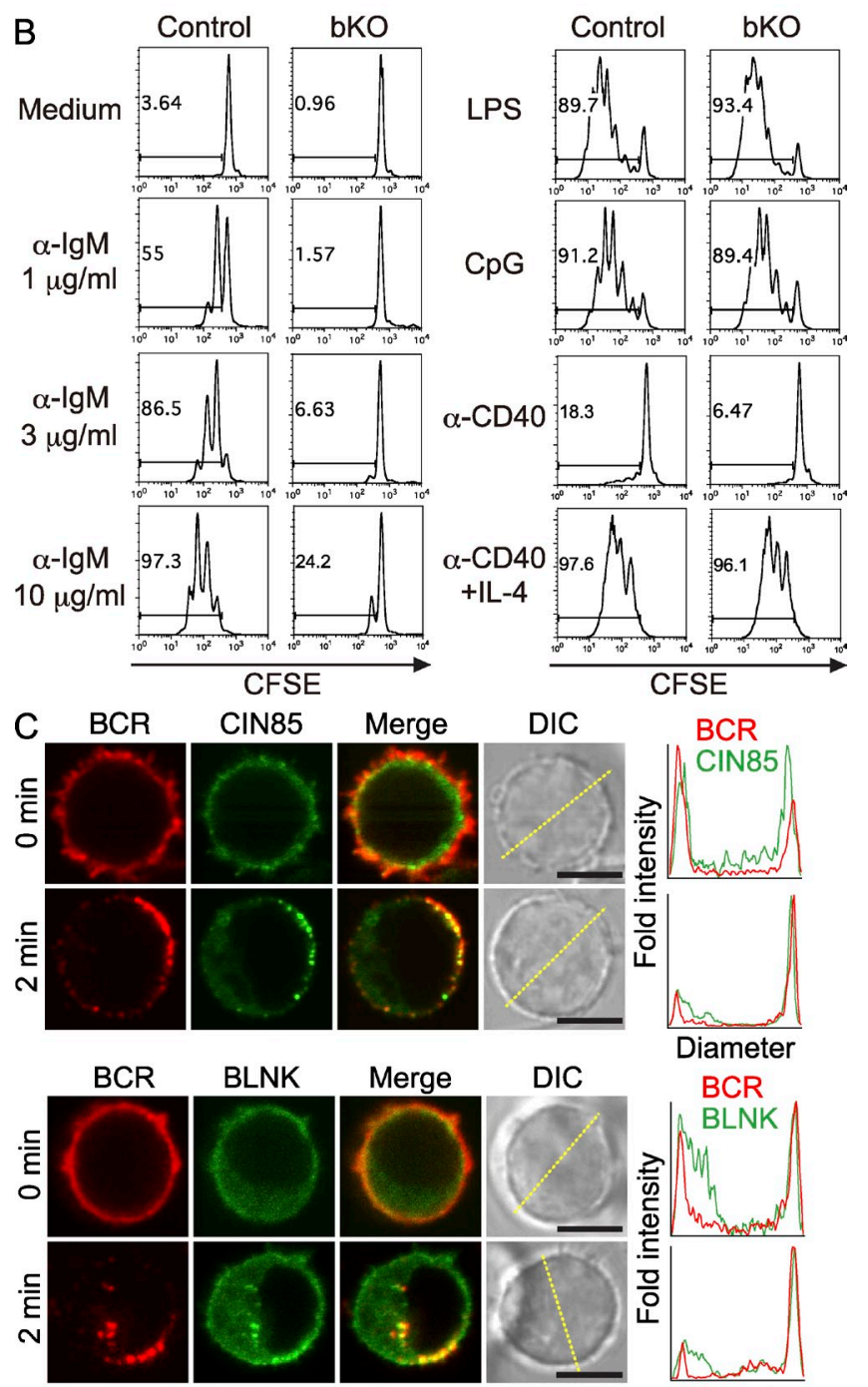

DIC
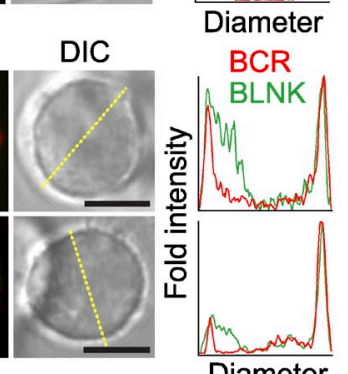

Figure 4. $B C R$-induced proliferation and survival in vitro are impaired in CIN85 bKO mice. (A) Spleen B cells from each mouse were negatively purified with anti-CD43 magnetic beads and were cultured with $10 \mu \mathrm{g} / \mathrm{ml}$ anti-lgM F(ab') ${ }_{2}$ fragment, $10 \mu \mathrm{g} / \mathrm{ml}$ LPS, $100 \mathrm{nM} \mathrm{CpG}$, $2 \mu \mathrm{g} / \mathrm{ml}$ anti-CD40 antibody, $10 \mathrm{ng} / \mathrm{ml} \mathrm{IL-4,} \mathrm{or} 50 \mathrm{ng} / \mathrm{ml}$ BAFF. After $48 \mathrm{~h}$ of culture, the proportion of live cells was enumerated as percentage of TO-PRO-3-excluding cells. Results represent the mean \pm SD. $n=3$. ${ }^{*}, P<0.01$. (B) Purified spleen B cells were labeled with $5 \mu \mathrm{M}$ CFSE. These CFSE-labeled cells were then cultured with 1,3 , or $10 \mu \mathrm{g} / \mathrm{ml}$ anti-lgM $\mathrm{F}\left(\mathrm{ab}^{\prime}\right)_{2}$ fragment, LPS, CpG, anti-CD40 antibody, or anti-CD40 plus IL-4 as indicated. After the culture for $72 \mathrm{~h}$, cell division was measured by flow cytometry. Representative data from three independent experiments are likely to be required for expansion of B cells in response to TI-II antigens in vivo.

\section{CIN85 mediates BCR-induced B cell proliferation and survival in vitro}

To further elucidate the function of CIN85, we directly assessed the survival and proliferative response of mb1-cre; $\mathrm{CIN}^{\mathrm{f}} 5^{\mathrm{f} / \mathrm{Y}} \mathrm{B}$ cells to various stimuli in vitro. These mutant B cells exhibited defective survival after anti-IgM stimulation but not after other stimuli such as anti-CD40, LPS, IL-4, and BAFF (Fig. 4 A). We also assessed proliferation in response to anti-IgM stimulation with CFSE-labeled B cells from mutant and control mice. As shown in Fig. 4 B, the mb1-cre; CIN85 $5^{\mathrm{f} / \mathrm{Y}}$ B cells essentially failed to divide at doses of 1 and $3 \mu \mathrm{g} / \mathrm{ml}$ anti-IgM. At saturating doses of $10 \mu \mathrm{g} / \mathrm{ml}$ anti-IgM, the mutant $\mathrm{B}$ cells began to divide but to a lesser extent than control $B$ cells. No defects in proliferation were observed after stimulation with LPS, CpG, and anti-CD40 + IL-4. The proliferation of mb1-cre; CIN85 ${ }^{\mathrm{A} / \mathrm{Y}} \mathrm{B}$ cells in response to anti-CD40 ligation alone was somewhat decreased (Fig. 4 B).

Involvement of CIN85 in BCR signaling was further substantiated by imaging analysis using confocal microscopy. CIN85-GFP or BLNK-YFP was transduced to LPS-stimulated $\mathrm{B}$ cells, and BCR stimulation was performed by in vitro antibody cross-linking. Upon BCR stimulation, 90\% of B cells demonstrated dense CIN85-GFP clusters colocalizing with BCR ( $n=50$, a representative of three independent experiments; Fig. 4 C, top). This clustering was similar to that of BLNK translocation to the plasma membrane. $88 \%$ of the cells formed BLNK-YFP clusters with the BCR $(n=50$, a representative of three independent experiments; Fig. $4 \mathrm{C}$, bottom). Thus, CIN85 participates specifically in BCRmediated proliferation and survival.

\section{CIN85 links the BCR to IKK}

Because BCR stimulation induces multiple signaling pathways that culminate in cellular responses such as proliferation and survival, we wished to address which pathways are perturbed in mb1-cre; CIN85 $5^{\mathrm{f} / \mathrm{Y}} \mathrm{B}$ cells. As proximal events, we

shown (A and B). (C) Purified spleen B cells were stimulated with LPS for $1 \mathrm{~d}$, and cells were transduced with retroviruses encoding CIN85-GFP or BLNK-YFP. $2 \mathrm{~d}$ after the infection, microscopic analysis was performed. Top, CIN85 bKO B cells expressing CIN85-GFP (green) were stained by rat anti-IgM antibody (red), fixed before (top) or 2 min after (bottom) crosslinking by anti-rat IgG antibody, and imaged by confocal microscopy. Histograms show fold fluorescent intensities of BCR (red) and CIN85-GFP (green) measured on the diagonal yellow line shown in the DIC images. Bars, $5 \mu \mathrm{m}$. Bottom, splenic B cells expressing BLNK-YFP (green) were stained by rat anti-IgM antibody (red), fixed before (top) or 2 min after (bottom) cross-linking by anti-rat IgG antibody, and imaged by confocal microscopy. More than 70\% of BCR clusters were colocalized by BLNK or CIN85 on the cell surface (BLNK, $74.9 \pm 11.6 \%$; CIN85, $71.9 \pm 19.9 \% ; n=20)$. Histograms show fold fluorescent intensities of BCR (red) and BLNK-YFP (green) measured on the diagonal yellow line shown in the DIC images. Bars, $5 \mu \mathrm{m} . n=50$. 

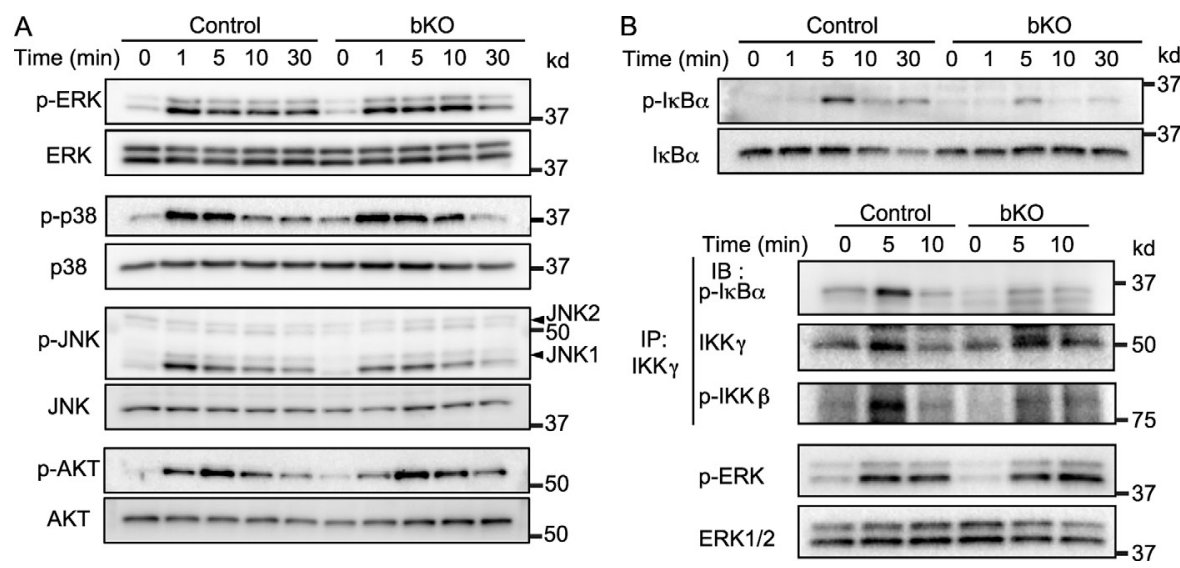

Figure 5. BCR-dependent activation of the canonical NF- $\mathrm{KB}$ pathway is impaired in CIN85 bKO B cells. (A) Purified spleen B cells were stimulated with $10 \mu \mathrm{g} / \mathrm{ml}$ anti-lgM $\mathrm{F}\left(\mathrm{ab} \mathrm{b}_{2}\right)_{2}$ for indicated times (minutes). The cells were lysed and subjected to SDS-PAGE. Transferred membranes were probed with the indicated antibodies. (B) Spleen B cells from control or CIN85 bKO mice were stimulated with $10 \mu \mathrm{g} / \mathrm{ml}$ anti-IgM $\mathrm{F}\left(\mathrm{ab} \mathrm{b}^{\prime}\right)_{2}$ fragment for the indicated times. After stimulation, some of the cells were subjected to SDS-PAGE to measure the phosphorylation status of $I_{\kappa} B \alpha$ (top). Other cells were collected, precipitated by anti-IKK- $\gamma$ antibody and subjected to an IKK kinase assay using GST-IкB $\alpha$ as a sub-

strate. The amount of phosphorylated GST-IкB $\alpha$ was detected by Western blotting as described in the Materials and methods (bottom). Phosphorylation status of IKK- $\beta$ was also analyzed by Western blotting. p-ERK was examined with whole cell lysate. Representative data of at least three independent experiments are shown.

first examined the status of overall tyrosine phosphorylation and calcium mobilization but detected no significant differences in either readout (Fig. S3 A). These results suggest that CIN85 is not essential for overall activation of proximal events of the BCR signaling cascade. Indeed, tyrosine phosphorylation status of Syk, BLNK, and PLC- $\gamma 2$ was also not significantly changed between control and mutant cells (Fig. S3 B).

NF- $\kappa B$, mitogen-activated protein kinase, and Akt pathways have been implicated in regulating $B$ cell proliferation and survival; however, the phosphorylation status of Akt, Erk1, Erk2, and p38 after anti-IgM stimulation was not significantly altered in mb1-cre; CIN85 ${ }^{\mathrm{A} / \mathrm{Y}} \mathrm{B}$ cells (Fig. $5 \mathrm{~A}$ ). In contrast, the level of IкB $\alpha$ phosphorylation was significantly decreased. The phosphorylation of JNK1 at $1 \mathrm{~min}$ was also decreased (Fig. 5, A and B). A defect in the canonical NF-кB pathway in mb1-cre; CIN85 $5^{\mathrm{A} / \mathrm{Y}} \mathrm{B}$ cells was also confirmed by an in vitro kinase assay of the IKK complex. After a 5-min stimulation of $\mathrm{BCR}$, the in vitro kinase activity of the IKK complex toward $\mathrm{I} \kappa \mathrm{B} \alpha$ was significantly impaired in mb1-cre; CIN $85^{\mathrm{t} / \mathrm{Y}}$ $\mathrm{B}$ cells (Fig. $5 \mathrm{~B}$ ). In contrast to the canonical NF- $\mathrm{kB}$ pathway, the BAFF-mediated noncanonical NF- $\mathrm{\kappa B}$ pathway functioned normally in mb1-cre; CIN $85^{\mathrm{f} / \mathrm{Y}} \mathrm{B}$ cells, as assessed by nuclear translocation of the p52 subunit of NF-кB2 (Fig. S4). Thus, mutant B cells display a selective partial defect in BCR coupling to IKK signaling pathway.

Previous studies with the transformed RBL-2H3 mast cell line showed that overexpression of CIN85 decreases the Syk protein level and enhances Fc $\varepsilon$ RI-mediated endocytosis (Peruzzi et al., 2007). Thus, we made a point of carefully checking the Syk protein level in mutant and control $\mathrm{B}$ cells but detected no significant difference (Fig. S5 A). To examine BCR-mediated endocytosis, we took two approaches: (1) in vitro BCR-mediated endocytosis; and (2) in vivo antigen-mediated endocytosis and subsequent antigen presentation by B cells. No significant differences between mutant and control B cells were detected in these two assays (Fig. S5, B and C).

\section{Expression of constitutively active IKK- $\boldsymbol{\beta}$ in B cells can substitute for some functions of CIN85}

Having demonstrated the importance of CIN85 in BCRmediated canonical NF- $\mathrm{\kappa B}$ activation, we reasoned that the defects in mb1-cre; CIN85 $5^{\mathrm{A} / \mathrm{Y}}$ mice should be restored by manipulations that enhance canonical NF- $\mathrm{\kappa B}$ signaling. To test this hypothesis, we crossed mb1-cre; CIN $85^{\mathrm{A} / \mathrm{Y}}$ mice with mice in which a cDNA encoding constitutively active IKK- $\beta$, preceded by a loxP-flanked STOP cassette, is knocked into the ubiquitously expressed ROSA26 locus (mb1-cre; CIN85 ${ }^{\mathrm{f} / \mathrm{Y}}$; R26Stop ${ }^{\mathrm{A}}$ IKK- $\beta$ ca; Sasaki et al., 2006). As shown in Fig. 6 A, mb1-cre; CIN85 ${ }^{\mathrm{A} / \mathrm{Y}} \mathrm{B}$ cells from these mice express constitutively active IKK- $\beta$; however, the defect in B-1a cell development was not corrected (Fig. 6 B). In contrast, TI-II immune responses, as judged by anti-NP IgM titers, were almost completely restored by introduction of constitutively active IKK- $\beta$ (Fig. 6 C). Well correlated with restoration of TI-II immune response, in vitro BCR-mediated proliferation and survival were also restored (Fig. 6, D and E). Together, these results suggest that defective $T$ cell-independent immune responses could be, at least partly, explained by defective BCR-mediated canonical NF- $\mathrm{BB}$ activation in mb1-cre; $\mathrm{CIN} 85^{\mathrm{A} / \mathrm{Y}}$ mice.

\section{DISCUSSION}

Although a slightly decreased number of splenic T2, T3, and mature B cells was observed in the absence of CIN85, overall B-2 B cell development took place normally. In contrast, there was a deficiency in the peritoneal B-1 cell compartment. The selective B-1 deficiency fits with the idea that BCR cross-linking by self-antigen is required for maintenance of this self-renewing B cell compartment (Hayakawa et al., 1999). In this regard, MZ B cells are thought to be similarly selected by self-antigen to the B-1 population (Wen et al., 2005), as there are shared characteristics between B-1 and MZ B cells, raising the question of why MZ B cells develop normally in the mutant mice. There are several, not necessarily 


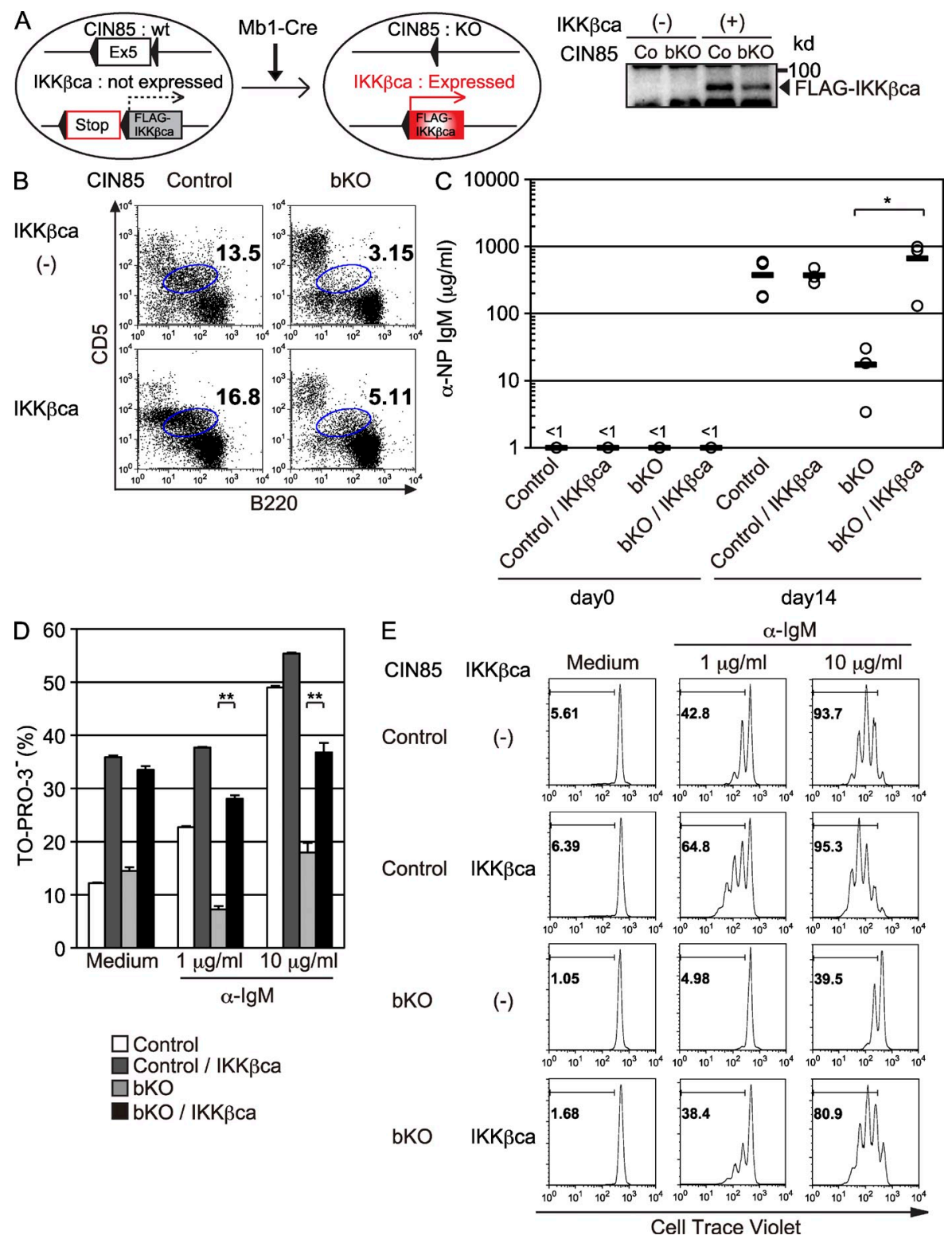

Figure 6. Impaired TI-II responses in CIN85 bKO mice are restored by introduction of constitutively active IKK- $\beta$. (A) Schematic design of the experiment. In the presence of Cre, exon 5 of Cin85 is deleted and Flag-IKK- $\beta$ ca is expressed. To confirm the expression of FLAG-tagged IKK$\beta c a$, spleen $B$ cells from control (Co) and CIN85 bKO were subjected to Western blotting. (B) Peritoneal cells from control, CIN85 bKO, CIN85 control; R26IKK $\beta \mathrm{ca}^{\mathrm{K} / \mathrm{wt}}$, and CIN85 bKO; R26IKKßcakl/wt mice were analyzed by flow cytometry. Numbers indicate the percentages of $B-1$ a cells within the gate. (C) $3 \times 10^{6}$ purified spleen $B$ cells from mice of indicated genotypes were injected i.v. into Rag $1^{-1-}$ mice. On the next day, $50 \mu \mathrm{g}$ NP-Ficoll was injected i.p. Sera were collected $14 \mathrm{~d}$ later and the anti-NP IgM titer was measured by ELISA. Circles represent each titer and black bars represent the means. ${ }^{*}, P<0.05$ (D) Purified spleen B cells from each genotype were cultured with medium alone or anti-IgM F(ab') ${ }_{2}$ fragment for $48 \mathrm{~h}$ and the proportion of live cells were enumerated using TO-PRO-3. Data are shown as the mean \pm SD. ${ }^{* *}, P<0.01$ (E) Spleen B cells of indicated genotypes were labeled with $5 \mu \mathrm{M}$ CellTrace violet and cultured with medium alone or anti-IgM $\mathrm{F}\left(\mathrm{ab} \mathrm{b}^{\prime}\right)_{2}$ fragment for $72 \mathrm{~h}$ and fluorescence intensity was measured by flow cytometry. Each group consisted of three mice (B and $\mathrm{C})$ and representative data of three independent experiments are shown ( $D$ and $E$ ).

Indeed, mice devoid of B-1 and MZ $\mathrm{B}$ cells, such as CD19 ${ }^{-/-}$mice, can still evoke TI-II responses (Rickert et al., 1995; Shih et al., 2002). Thus, the almost complete failure of mb1cre; $\mathrm{CIN} 85^{\mathrm{f} / \mathrm{Y}}$ mice to respond to

mutually exclusive, possibilities. First, the decreased signaling resulting from loss of CIN85 is still sufficient to promote the maturation and/or survival of the MZ subset but not the B-1 subset. Given the requirement for BAFF in development of the MZ, but not the B-1 subset (Schiemann et al., 2001), an alternative possibility is that the BAFF-R signal might compensate for the decreased BCR-mediated signal in MZ B cells, thereby promoting their development. Indeed, the BAFF-R-mediated survival signal is normal in mb1-cre; CIN85 ${ }^{\mathrm{f} / \mathrm{Y}} \mathrm{B}$ cells (Fig. $4 \mathrm{~A}$ and Fig. S4).

TI-II antigens, which are typically derived from polysaccharides and consist of complex repeating units, drive B cell responses by extensive cross-linking of cognate BCRs. Although B-1 and MZ B cells have been thought to be responsible for the initial TI-II response, FO B-2 B cells also participate in the overall TI-II antibody responses (Swanson et al., 2010).
TI-II antigens (Fig. 3 A) cannot be simply accounted for by the B-1 deficiency in the mutant mice.

In the case of $\mathrm{MZ} \mathrm{B}$ cells, their importance for delivering complement-opsonized antigens such as Ficoll has been recently appreciated (Cinamon et al., 2008). According to this model, MZ B cells shuttle between MZ and the B cell follicles, thereby capturing blood-borne large antigens and subsequently transporting them from the blood to splenic FO DCs, which then display the antigen to B cells. As shown in Fig. 3 C, this process appears to occur normally in the mutant mice, suggesting that antigen-specific B cells in the spleen are capable of recognizing cognate antigens. Therefore, the inability of the mutant mice to induce antibody responses is most likely explained by poor expansion and survival of antigen-specific MZ and FO B cells, as demonstrated in Fig. 3 D. In fact, BCRmediated proliferation/survival and in vivo TI-II responses 
were restored by introduction of a constitutively active B cellspecific IKK- $\beta$ in the mutant mice. Despite restoration of TI-II responses by active IKK- $\beta, \mathrm{B}-1 \mathrm{~B}$ cell was not rescued. Assuming that an optimal intensity of $\mathrm{NF}-\kappa \mathrm{B}$ signal is required for B-1 B cell development, it is possible that the intensity of $N F-\kappa B$ signaling induced by our IKK- $\beta$ mutant might be too strong, thereby interfering with B-1 B cell development. An alternative possibility is that the canonical NF- $\kappa \mathrm{B}$ pathway is necessary, but not sufficient, for the development of B-1 B cells and that other pathways, such as JNK1, are also required.

Based on studies of $293 \mathrm{~T}$ cells, after receptor tyrosine kinase activation, Cbl-CIN85 interaction is thought to be essential for the promotion of the initial steps of endocytosis and pinching off of the endocytic vesicles (Dikic, 2002). Cbl, one of the RING-type E3 ubiquitin ligases, is recruited to active tyrosine phosphorylated PTKs through its SH2 domain and ubiquitinated the receptors, which causes their endocyticdependent degradation (Joazeiro et al., 1999). In addition, the interaction of $\mathrm{Cbl}$ with PTKs also induces tyrosine phosphorylation of $\mathrm{Cbl}$, which unmasks its proline-rich determinants that can then interact with $\mathrm{SH} 3$ domains of CIN85 (Szymkiewicz et al., 2002). The association between $\mathrm{Cbl}$ and CIN85 is required for ligand-induced mono-ubiquitination of CIN85, which has been thought to be important for recognition of proteins of the endocytic machinery. This mechanism has been shown to operate in physiological settings as well. By using neuron-specific CIN85 knockout mice, Shimokawa et al. (2010) have recently demonstrated the involvement of CIN85 in endocytosis of the D2 dopamine receptor (D2DR), which belongs to the seven-transmembrane $G$ protein-coupled receptor superfamily. But, in contrast to the D2DR, endocytosis of the D1 dopamine receptor was not affected by the loss of CIN85, suggesting the coexistence of CIN85-dependent and -independent mechanisms. Thus, considering the previous evidence that BCR down-modulation and Ig $\alpha$ ubiquitination are inhibited in $\mathrm{Cbl}^{-/-} \mathrm{Cbl-b^{-/- }}$ B cells (Kitaura et al., 2007), one possible interpretation for the apparently normal in vitro BCR internalization in mb1-cre; CIN85 $5^{\mathrm{f} / \mathrm{Y}} \mathrm{B}$ cells is that the BCR utilizes the Cbl-dependent but CIN85-independent mechanism. As discussed later in this section, this might be caused by the preferential association of CIN85 to BLNK rather than to Cbl/Cbl-b in the BCR signaling context. Our results nevertheless allow for the alternative possibility that CIN85 and CD2AP participate, redundantly, in BCR endocytosis.

Our studies indicate that CIN85 has a positive role in BCR-mediated survival and proliferation by participating in canonical NF- $\mathrm{KB}$ signaling. Although PLC- $\gamma 2$ and subsequent $\mathrm{PKC}-\beta$ activation are involved in BCR-mediated NF- $\kappa$ B activation (Saijo et al., 2002; Su et al., 2002), the apparently normal tyrosine phosphorylation status of PLC- $\gamma 2$ and subsequent calcium mobilization in mb1-cre; CIN85 $5^{\mathrm{f} / \mathrm{Y}}$ $\mathrm{B}$ cells suggest that CIN85 affects canonical NF- $\mathrm{KB}$ activation independently of PLC- $\gamma 2 / \mathrm{PKC}-\beta$. Thus, given the previous evidence that defects in BCR-mediated NF- $\mathrm{BB}$ signaling pathways are induced by mutations in CARMA1, Bcl10,
MALT1, and TAK1 (Shinohara and Kurosaki, 2009), it is reasonable to speculate that CIN85 interacts with such complexes, directly or indirectly.

The precise biochemical mechanism by which CIN85 activates IKK- $\beta$ remains unclear. One possibility is that the protein-protein interaction motifs of CIN85 might allow it to recruit additional signaling molecules, such as CARMA1, $\mathrm{Bcl10}$, and MALT1, that could mediate IKK- $\beta$ activation directly or indirectly. Considering that CIN85 was recruited to the plasma membrane quite rapidly after BCR cross-linking, these interactions might have two consequences: membrane recruitment of CIN85 partners and their conformational changes. With regard to membrane recruitment, a role for the SH3 domain of CARMA1 was strongly implicated by studies using a lack-of-function CARMA1 mutant in the Jurkat $\mathrm{T}$ cell line (Wang et al., 2004). Thus, the proline-rich region of CIN85 might contribute to its association with the CARMA1 $\mathrm{SH} 3$ domain and its subsequent membrane recruitment. When we used a lower concentration of anti-IgM compared with Fig. $4 \mathrm{C}$, we could not observe significant association between BCR and CIN85 (not depicted). This suggests that only strong BCR signal, such as in the case of TI-II responses, utilizes CIN85 for membrane recruitment of its partner molecules, whereas the weak signal, such as tonic BCR signal, might not necessarily require CIN85 (Lam et al., 1997; Monroe, 2006), providing the potential explanation of why development of mature FO B cells was only marginally affected in the absence of CIN85.

In addition to the conventional protein-protein interactions mentioned in the previous paragraph, given the recent evidence that the SH3 C domain of CIN85 can function as an ubiquitin-binding domain (UBD; Bezsonova et al., 2008), CIN85 might exert its function through binding to ubiquitinated proteins. Indeed, ubiquitination of IKK- $\gamma$ and TRAF6 has already been reported in the context of antigen receptor signaling being important for $\mathrm{NF}-\kappa \mathrm{B}$ activation (Sun et al., 2004). In addition, several NF- $\kappa B$ components, for instance, TAK1-binding protein TAB2, are known to contain the UBD (Kanayama et al., 2004). Thus, it is possible that the CIN85 UBD contributes to the assembly of complexes with targets such as IKK- $\gamma$ and TRAF6, which are reversibly and covalently modified by specific ubiquitin chains in the BCR signaling context. It is also important to note that CIN85, like CD2AP, is capable of facilitating actin polymerization by inhibiting actin-capping proteins (Hutchings et al., 2003). Given the importance of actin cytoskeleton dynamics in NF- $\mathrm{KB}$ signaling (Legrand-Poels et al., 2007), deregulation of this process might occur in mb1-cre; CIN85 ${ }^{\mathrm{fl} / \mathrm{Y}}$ B cells, possibly leading to defective NF- $\mathrm{KB}$ signaling.

Assuming that CIN85 and CD2AP have redundant functions, the question arises of why T cells lacking CD2AP show enhanced TCR-mediated proliferation. It has been observed that both CIN85 and CD2AP can bind to BLNK but not SLP-76 (Wienands, J., personal communication). Because BCR and TCR use BLNK or SLP-76, respectively, as a critical signaling molecule, it is possible that there is a preferential 
association of CIN85/CD2AP with BLNK in the BCR signaling context, thereby allowing both CIN85 and CD2AP to participate in NF- $\kappa \mathrm{B}$ activation, whereas in the case of TCR signaling, CIN85 and CD2AP associate with Cbl, thereby coupling them to an endocytotic pathway. Thus, depending on their binding partners, CIN85 and CD2AP could induce distinct biological outcomes. As an extension of this hypothesis, skewing the association of CIN85 and CD2AP toward $\mathrm{Cbl}$ in anergic anti-HEL B cells could explain why these cells shut off NF-KB and JNK signaling and display an enhancement of endocytosis (Jun and Goodnow, 2003; Bléry et al., 2006).

\section{MATERIALS AND METHODS}

Mice. To generate Flox-CIN85 mice, a PCR-amplified Cin85 exon 5 containing genomic fragment was flanked with two loxP sites and subcloned into a vector that contained a neomycin resistance gene, a diphtheria toxin A gene, and a 5.7-kbp 5' and a 2.0-kbp 3' homology Cin 85 arm. The targeting vector was electroporated into $\mathrm{C} 57 \mathrm{BL} / 6$ background Bruce 4 embryonic stem cells (Köntgen et al., 1993) and selection was performed with G418 (Invitrogen). Correctly targeted clones were identified by Southern blotting. The neomycin resistant gene was removed by transiently transfecting a Cre expression vector as described elsewhere (Yamada et al., 2008). Targeted ES clones were injected into blastocysts from $\mathrm{BALB} / \mathrm{c}$ mice to obtain chimeric mice. These chimeric mice were then crossed with C57BL/6 mice to obtain germline transmitted animals. To generate B cell-specific CIN85 knockout mice, floxed mice were crossed with mb1-Cre knockin (KI) mice (Hobeika et al., 2006). Mb1-Cre knockin mice were provided by E. Hobeika and M. Reth (Max Planck Institute for Immunobiology, Freiburg, Germany). Rosa26-stop-FLAG-IKK- $\beta$ ca mice have been described previously (Sasaki et al., 2006). Mice were maintained under specific pathogen-free conditions. All the protocols for animal experiments were approved by the RIKEN Animal Research Committee.

Flow cytometric analysis. Single cell suspensions lysed of red blood cells were stained with fluorochrome-conjugated antibodies. Stained cells were analyzed with a FACSCalibur or FACSCanto II (BD). Anti-AA4.1, B220, Fas, GL7, IgD, IgM, MHC class II, CD3, CD4, CD5, CD8, CD21, CD23, and CD86 antibodies were purchased from $\mathrm{BD}$, eBioscience, or BioLegend. NP-binding B cells were detected using (4-hydroxy-5-indo-3-nitrophenyl)acetyl (NIP)-BSA-PE.

For the detection of TNP-Ficoll binding cells, spleen cells were recovered from the mice injected with $100 \mu \mathrm{g}$ TNP-Ficoll i.v. These cells were then stained with biotin-conjugated anti-TNP antibody (BD) in combination with streptavidin-FITC and analyzed using a FACSCanto II.

Immunohistology. Small pieces of spleen were embedded in OCT compound (Sakura) and frozen at $-80^{\circ} \mathrm{C}$. Frozen sections $(8 \mu \mathrm{m})$ were fixed and stained with Alexa Fluor 488-conjugated anti-MAdCAM-1 (BioLegend), biotin-conjugated anti-TNP, Alexa Fluor 647-conjugated B220 antibodies (BD), and Alexa Fluor 546-conjugated streptavidin (Invitrogen). Images were obtained using BIOREVO (Keyence).

Induction of immune responses. For measuring TI-II antigen responses, mice were immunized with $50 \mu \mathrm{g} \mathrm{NP}{ }_{28}$-Ficoll (Biosearch Technologies) i.p. To examine the TD antigen response, $100 \mu \mathrm{g}$ NP-CGG precipitated with Imject Alum (Thermo Fisher Scientific) was injected i.p. 6 wk later, $50 \mu \mathrm{g}$ of soluble NP-CGG was injected i.p. to induce recall responses. TI-II response in ROSA26-stop-FLAG-IKK- $\beta$ ca mice was examined by an adoptive transfer experiment. In brief, B cells were purified from the spleen of these mice by depletion of activated B cells and non-B cells with anti-CD43 microbeads using autoMACS (Miltenyi Biotec) and $3 \times 10^{6}$ of purified cells were injected into $\mathrm{Rag} 1^{-/-}$mice i.v. On the next day, the recipient mice were immunized i.p. with $50 \mu \mathrm{g}$ NP-Ficoll. Sera were collected before and every week after the immunization and anti-NP IgM titers were measured by ELISA.

ELISA. 96-well flat-bottom plates were coated with $2 \mu \mathrm{g} / \mathrm{ml} \mathrm{NP}_{10}$-BSA followed by blocking with $0.5 \%$ BSA in PBS. Serially diluted samples were incubated at $4^{\circ} \mathrm{C}$ for $1 \mathrm{~d}$. After washing with PBS/0.5\% Tween-20, horseradish peroxidase-conjugated anti-mouse IgM or IgG3 antibodies (SouthernBiotech) were appropriately diluted and added to the wells. SureBlue (KPL) was used as the substrate and absorbance at $450 \mathrm{~nm}$ was measured using a microplate reader (Bio-Rad Laboratories). For detecting high-affinity anti$\mathrm{NP}$ IgG1 antibody, $\mathrm{NP}_{1}$-BSA was used as a capture antigen.

In vitro $B$ cell culture. $B$ cells were purified from the splenocytes using anti-CD43 microbeads and AutoMACS (Miltenyi Biotec). Collected cells were labeled with $5 \mu \mathrm{M}$ CFSE (Dojindo) or CellTrace violet (Invitrogen) at $37^{\circ} \mathrm{C}$ for $20 \mathrm{~min}$. Labeled cells were cultured in RPMI1640 supplemented with $10 \% \mathrm{FBS}, 50 \mu \mathrm{M}$ 2-ME, and penicillin/streptomycin. Anti-IgM F(ab') (Jackson ImmunoResearch Laboratories), LPS (Sigma-Aldrich), CpG, antiCD40 (BD), and IL-4 (R\&D Systems) were added as indicated. After $72 \mathrm{~h}$ of culture, cell division was measured by FACSCanto II. For analyzing cell viability, negatively purified spleen $B$ cells were cultured with anti-IgM $\mathrm{F}(\mathrm{ab})_{2}$, LPS, CpG, anti-CD40, IL-4, or BAFF (R\&D Systems). After $48 \mathrm{~h}$ of culture, the dead cells were labeled with TO-PRO-3 (Invitrogen) and the proportion of the live cells was enumerated as the percentage ofTO-PRO-3negative cells.

Western blotting. Negatively purified spleen B cells were stimulated with $10 \mu \mathrm{g} / \mathrm{ml}$ anti-IgM F(ab') $)_{2}$ for the indicated periods and lysed with RIPA buffer. Cell lysates were boiled with SDS sample buffer and subjected to SDS-PAGE followed by transfer to PVDF membranes (Millipore). The membranes were blocked and incubated with the following antibodies to the following antigens: phospho I $\kappa \mathrm{B} \alpha$, phospho ERK, phospho p38, phospho AKT (Ser473), phospho BLNK, BLNK, and phospho Syk (Cell Signaling Technology); IкB $\alpha$, ERK1, ERK2, p38, JNK1/3, AKT, Syk, PLC- $\gamma 2$, and phospho IKK- $\beta$ (Santa Cruz Biotechnology, Inc.); phospho JNK (Promega); IKK- $\gamma(\mathrm{BD})$; and GAPDH and phosphotyrosine (Millipore). Anti-CIN85 polyclonal antibody was obtained by immunizing rabbits with CIN85 peptideconjugated glutathione $S$-transferase (GST) as described previously (Oh-hora et al., 2003). Anti-CD2AP antibody was provided by A. Shaw (Washington University School of Medicine, St. Louis, MO). Then the membranes were incubated with the appropriate alkaline phosphatase-conjugated secondary antibody, followed by detection with a chemiluminescent substrate (Millipore). The IKK kinase assay was performed as previously described (Shinohara et al., 2007). In brief, spleen B cells from the control or CIN85 bKO mice were stimulated with $10 \mu \mathrm{g} / \mathrm{ml}$ anti-IgM F $(\mathrm{ab})_{2}$ fragment for the indicated times. After stimulation, cells were lysed and the IKK complex was precipitated with anti-IKK- $\gamma$ antibody. IKK kinase activity was measured using GST-IкB $\alpha$ as a substrate. The amount of phosphorylated GST-IкB $\alpha$ was detected by Western blotting.

Quantitative RT-PCR. Total RNA was extracted using TRIZOL (Invitrogen) according to the manufacturer's instructions. DNase I (Invitrogen)treated RNA was reverse transcribed using Super Script III (Invitrogen). Quantitative PCR was performed using SYBR Green (Invitrogen) and ABI Prism 7000 (Applied Biosystems). The following primers were used: 5'-GTGGAGGCCATAGTGGAGTT-3' and 5'-CACGCTGATTGTCAGCTCAT-3' (Cin85-l); 5'-CCCACAGACTTGCCTGAGA-3' and 5'-ACTGGATACATCGTGCATGG-3' (Cin85- $\Delta A$ ); and $5^{\prime}$-GCTCTGTGAAACTTCGGACA-3' and 5'-CCCAGAGGCTGTAGGATTAAAG-3' (Cd2ap).

Analysis of B cell function. To examine the BCR-mediated calcium response, purified B cells were loaded with Indo-1 AM (Dojindo) and Pluronic F-127 (Invitrogen) at $37^{\circ} \mathrm{C}$ for $45 \mathrm{~min}$. Cells were stimulated with $10 \mu \mathrm{g} / \mathrm{ml}$ 
anti-IgM F $\left(\mathrm{ab}^{\prime}\right)_{2}$ and the fluorescence was detected using LSR (BD) as described previously (Baba et al., 2008).

For measuring BCR internalization, B cells were incubated with $0.5,1$, or $5 \mu \mathrm{g} / \mathrm{ml}$ biotin-conjugated anti-IgM antibody (BD) on ice for $20 \mathrm{~min}$. After washing with ice cold PBS, the cells were kept on ice or incubated at $37^{\circ} \mathrm{C}$ for indicated times followed by incubation with streptavidinallophycocyanin (APC; BD) and analyzed using a FACSCanto II.

To examine in vivo antigen presentation by B cells, $100 \mu \mathrm{g}$ NP-E $\alpha-G F P$ (Itano et al., 2003; Pape et al., 2007) was injected i.p. into the mice. This construct was generated by K.A. Pape and M.K. Jenkins (University of Minnesota Medical School, Minneapolis, MN). After $12 \mathrm{~h}$, splenocytes were collected and antigen-presenting B cells were detected by incubation with biotin-conjugated YAe antibody (eBioscience), followed by staining with NIP-BSA-PE, anti-B220, and streptavidin-APC. The cells were analyzed using a FACSCanto II.

Subcellular localization of CIN85. Mouse CIN85 was fused to the $\mathrm{N}$ terminus of GFP or CFP and subcloned to pMXs retroviral vector. pMXs vector was provided by T. Kitamura (University of Tokyo, Tokyo, Japan). Purified B cells were cultured with $10 \mu \mathrm{g} / \mathrm{ml}$ LPS for $1 \mathrm{~d}$, and GFP-fused CIN85 or YFP-fused BLNK was retrovirally transduced into LPS-stimulated B cells. 2 d later after the infection, the cells were incubated with $2 \mu \mathrm{g} / \mathrm{ml}$ anti-IgM antibody followed by cross-linking with fluorochrome-conjugated anti-rat $\operatorname{IgG}$ antibody. The cells were fixed and imaged by confocal microscopy (Leica).

Statistical analysis. Statistical analyses were performed using two-tailed unpaired Student's $t$ test.

Online supplemental material. Fig. S1 shows the expression of CIN85 and CD2AP in immune cells. Fig. S2 shows TD immune responses in CIN85 bKO mice. Fig. S3 shows normal activation of BCR-proximal signaling molecules in CIN85 bKO mice. Fig. S4 shows BAFF-induced noncanonical $\mathrm{NF}-\kappa \mathrm{B}$ activation in CIN85 bKO mice. Fig. S5 shows the effects of CIN85 deletion on protein degradation and internalization. Online supplemental material is available at http://www.jem.org/cgi/content/full/jem.20102665/DC1.

We thank Dr. E. Hobeika and Dr. M. Reth for mb1-Cre mice, Dr. K.A. Pape and Dr. M.K. Jenkins for providing us with the E $\alpha$ GFP construct, Dr. T. Kitamura for pMXs vector, Dr. A. Shaw for anti-CD2AP antibody, Dr. H. Shinohara for technical advice, Dr. J. Wienands for reagents and critical discussion, and Dr. T. Oellerich and Dr. J. Wienands for communicating unpublished results.

This work was supported by grant-in-Aid to T. Kurosaki from the Ministry of Education, Culture, Sports, Science, and Technology in Japan and by a grant to T. Kurosaki from Japan Science and Technology Agency, Core Research of Evolutional Science and Technology. This work was also supported by RIKEN Special Postdoctoral Researchers Program to K. Kometani.

The authors have no conflicting financial interests.

Submitted: 22 December 2010

Accepted: 25 May 2011

\section{REFERENCES}

Anderson, S.M., M.M. Tomayko, A. Ahuja, A.M. Haberman, and M.J. Shlomchik. 2007. New markers for murine memory B cells that define mutated and unmutated subsets. J. Exp. Med. 204:2103-2114. doi:10 $.1084 / \mathrm{jem} .20062571$

Baba,Y., K. Nishida, Y. Fujii, T. Hirano, M. Hikida, and T. Kurosaki. 2008 Essential function for the calcium sensor STIM1 in mast cell activation and anaphylactic responses. Nat. Immunol. 9:81-88. doi:10 $.1038 /$ ni1546

Bezsonova, I., M.C. Bruce, S. Wiesner, H. Lin, D. Rotin, and J.D. Forman-Kay 2008. Interactions between the three CIN85 SH3 domains and ubiquitin: implications for CIN85 ubiquitination. Biochemistry. 47:8937-8949. doi:10.1021/bi800439t

Bléry, M., L. Tze, L.A. Miosge, J.E. Jun, and C.C. Goodnow. 2006. Essential role of membrane cholesterol in accelerated $\mathrm{BCR}$ internalization and uncoupling from NF-кB in B cell clonal anergy. J. Exp. Med. 203:17731783. doi:10.1084/jem.20060552

Buchman, V.L., C. Luke, E.B. Borthwick, I. Gout, and N. Ninkina. 2002. Organization of the mouse Ruk locus and expression of isoforms in mouse tissues. Gene. 295:13-17. doi:10.1016/S0378-1119(02)00821-1

Cinamon, G., M.A. Zachariah, O.M. Lam, F.W. Foss Jr., and J.G. Cyster. 2008. Follicular shuttling of marginal zone B cells facilitates antigen transport. Nat. Immunol. 9:54-62. doi:10.1038/ni1542

Dikic, I. 2002. CIN85/CMS family of adaptor molecules. FEBS Lett. 529:110-115. doi:10.1016/S0014-5793(02)03188-5

Dikic, I., and S. Giordano. 2003. Negative receptor signalling. Curr. Opin. Cell Biol. 15:128-135. doi:10.1016/S0955-0674(03)00004-8

Dustin, M.L., M.W. Olszowy, A.D. Holdorf, J. Li, S. Bromley, N. Desai, P. Widder, F. Rosenberger, P.A. van der Merwe, P.M. Allen, and A.S. Shaw. 1998. A novel adaptor protein orchestrates receptor patterning and cytoskeletal polarity in T-cell contacts. Cell. 94:667-677. doi:10.1016/ S0092-8674(00)81608-6

Fu, C., C.W. Turck, T. Kurosaki, and A.C. Chan. 1998. BLNK: a central linker protein in B cell activation. Immunity. 9:93-103. doi:10.1016/ S1074-7613(00)80591-9

Goitsuka, R.,Y. Fujimura, H. Mamada, A. Umeda, T. Morimura, K. Uetsuka, K. Doi, S. Tsuji, and D. Kitamura. 1998. BASH, a novel signaling molecule preferentially expressed in B cells of the bursa of Fabricius. J. Immunol. 161:5804-5808.

Gout, I., G. Middleton, J. Adu, N.N. Ninkina, L.B. Drobot, V. Filonenko, G. Matsuka, A.M. Davies, M. Waterfield, and V.L. Buchman. 2000. Negative regulation of PI 3-kinase by Ruk, a novel adaptor protein. EMBO J. 19:4015-4025. doi:10.1093/emboj/19.15.4015

Guinamard, R., M. Okigaki, J. Schlessinger, and J.V. Ravetch. 2000. Absence of marginal zone B cells in Pyk-2-deficient mice defines their role in the humoral response. Nat. Immunol. 1:31-36.

Hardy, R.R., and K. Hayakawa. 2001. B cell development pathways. Annu. Rev. Immunol. 19:595-621. doi:10.1146/annurev.immunol.19.1.595

Hayakawa, K., M. Asano, S.A. Shinton, M. Gui, D. Allman, C.L. Stewart, J. Silver, and R.R. Hardy. 1999. Positive selection of natural autoreactive B cells. Science. 285:113-116. doi:10.1126/science.285.5424.113

Hobeika, E., S. Thiemann, B. Storch, H. Jumaa, P.J. Nielsen, R. Pelanda, and M. Reth. 2006. Testing gene function early in the B cell lineage in mb1-cre mice. Proc. Natl. Acad. Sci. USA. 103:13789-13794. doi:10 $.1073 /$ pnas. 0605944103

Hutchings, N.J., N. Clarkson, R. Chalkley, A.N. Barclay, and M.H. Brown. 2003. Linking the $\mathrm{T}$ cell surface protein $\mathrm{CD} 2$ to the actin-capping protein CAPZ via CMS and CIN85. J. Biol. Chem. 278:22396-22403. doi:10.1074/jbc.M302540200

Itano, A.A., S.J. McSorley, R.L. Reinhardt, B.D. Ehst, E. Ingulli, A.Y. Rudensky, and M.K. Jenkins. 2003. Distinct dendritic cell populations sequentially present antigen to CD4 $\mathrm{T}$ cells and stimulate different aspects of cell-mediated immunity. Immunity. 19:47-57. doi:10.1016/S1074-7613(03)00175-4

Joazeiro, C.A., S.S. Wing, H. Huang, J.D. Leverson, T. Hunter, and Y.C. Liu. 1999. The tyrosine kinase negative regulator c-Cbl as a RING-type, E2-dependent ubiquitin-protein ligase. Science. 286:309-312. doi:10 $.1126 /$ science. 286.5438 .309

Jun, J.E., and C.C. Goodnow. 2003. Scaffolding of antigen receptors for immunogenic versus tolerogenic signaling. Nat. Immunol. 4:1057-1064. doi:10.1038/ni1001

Kanayama, A., R.B. Seth, L. Sun, C.K. Ea, M. Hong, A. Shaito, Y.H. Chiu, L. Deng, and Z.J. Chen. 2004. TAB2 and TAB3 activate the NF-kappaB pathway through binding to polyubiquitin chains. Mol. Cell. 15:535-548. doi:10.1016/j.molcel.2004.08.008

Kitaura, Y., I.K. Jang, Y. Wang, Y.C. Han, T. Inazu, E.J. Cadera, M. Schlissel, R.R. Hardy, and H. Gu. 2007. Control of the B cell-intrinsic tolerance programs by ubiquitin ligases $\mathrm{Cbl}$ and Cbl-b. Immunity. 26:567-578. doi:10.1016/j.immuni.2007.03.015

Köntgen, F., G. Süss, C. Stewart, M. Steinmetz, and H. Bluethmann. 1993. Targeted disruption of the MHC class II Aa gene in C57BL/6 mice. Int. Immunol. 5:957-964. doi:10.1093/intimm/5.8.957

Lam, K.P., R. Kühn, and K. Rajewsky. 1997. In vivo ablation of surface immunoglobulin on mature B cells by inducible gene targeting results in rapid cell death. Cell. 90:1073-1083. doi:10.1016/S0092-8674(00)80373-6 
Legrand-Poels, S., G. Kustermans, F. Bex, E. Kremmer, T.A. Kufer, and J Piette. 2007. Modulation of Nod2-dependent NF-kappaB signaling by the actin cytoskeleton. J. Cell Sci. 120:1299-1310. doi:10.1242/jcs.03424

Molfetta, R., F. Belleudi, G. Peruzzi, S. Morrone, L. Leone, I. Dikic, M. Piccoli, L. Frati, M.R. Torrisi, A. Santoni, and R. Paolini. 2005. CIN85 regulates the ligand-dependent endocytosis of the IgE receptor: a new molecular mechanism to dampen mast cell function. J. Immunol. 175:4208-4216.

Monroe, J.G. 2006. ITAM-mediated tonic signalling through pre-BCR and BCR complexes. Nat. Rev. Immunol. 6:283-294. doi:10.1038/nri1808

Navarro, M.N., G. Nusspaumer, P. Fuentes, S. González-García, J. Alcain, and M.L. Toribio. 2007. Identification of CMS as a cytosolic adaptor of the human pTalpha chain involved in pre-TCR function. Blood. 110:43314340. doi:10.1182/blood-2007-06-094938

Oh-hora, M., S. Johmura, A. Hashimoto, M. Hikida, and T. Kurosaki. 2003. Requirement for Ras guanine nucleotide releasing protein 3 in coupling phospholipase C- $\gamma 2$ to Ras in B cell receptor signaling. J. Exp. Med. 198:1841-1851. doi:10.1084/jem.20031547

Pape, K.A., D.M. Catron, A.A. Itano, and M.K. Jenkins. 2007. The humoral immune response is initiated in lymph nodes by $\mathrm{B}$ cells that acquire soluble antigen directly in the follicles. Immunity. 26:491-502. doi:10.1016/j.immuni.2007.02.011

Peruzzi, G., R. Molfetta, F. Gasparrini, L.Vian, S. Morrone, M. Piccoli, L. Frati, A. Santoni, and R. Paolini. 2007. The adaptor molecule CIN85 regulates Syk tyrosine kinase level by activating the ubiquitin-proteasome degradation pathway. J. Immunol. 179:2089-2096.

Petrelli,A., G.F. Gilestro, S. Lanzardo, P.M. Comoglio, N. Migone, and S. Giordano 2002. The endophilin-CIN85-Cbl complex mediates ligand-dependent downregulation of c-Met. Nature. 416:187-190. doi:10.1038/416187a

Rickert, R.C., K. Rajewsky, and J. Roes. 1995. Impairment of T-celldependent B-cell responses and B-1 cell development in CD19deficient mice. Nature. 376:352-355. doi:10.1038/376352a0

Saijo, K., I. Mecklenbräuker, A. Santana, M. Leitger, C. Schmedt, and A. Tarakhovsky. 2002. Protein kinase $\mathrm{C} \beta$ controls nuclear factor $\kappa \mathrm{B}$ activation in B cells through selective regulation of the IкB kinase $\alpha . J$. Exp. Med. 195:1647-1652. doi:10.1084/jem.20020408

Sasaki, Y., E. Derudder, E. Hobeika, R. Pelanda, M. Reth, K. Rajewsky, and M. Schmidt-Supprian. 2006. Canonical NF-kappaB activity, dispensable for B cell development, replaces BAFF-receptor signals and promotes $\mathrm{B}$ cell proliferation upon activation. Immunity. 24:729-739. doi:10.1016/ j.immuni.2006.04.005

Schiemann, B., J.L. Gommerman, K.Vora, T.G. Cachero, S. Shulga-Morskaya, M. Dobles, E. Frew, and M.L. Scott. 2001. An essential role for BAFF in the normal development of B cells through a BCMA-independent pathway. Science. 293:2111-2114. doi:10.1126/science.1061964

Shih, T.A., E. Meffre, M. Roederer, and M.C. Nussenzweig. 2002. Role of BCR affinity in $\mathrm{T}$ cell dependent antibody responses in vivo. Nat. Immunol. 3:570-575. doi:10.1038/ni803

Shimokawa, N., K. Haglund, S.M. Hölter, C. Grabbe, V. Kirkin, N. Koibuchi, C. Schultz, J. Rozman, D. Hoeller, C.H. Qiu, et al. 2010. CIN85 regulates dopamine receptor endocytosis and governs behaviour in mice. EMBO J. 29:2421-2432. doi:10.1038/emboj.2010.120
Shinohara, H., and T. Kurosaki. 2009. Comprehending the complex connection between PKCbeta, TAK1, and IKK in BCR signaling. Immunol. Rev. 232:300-318. doi:10.1111/j.1600-065X.2009.00836.x

Shinohara, H., S. Maeda, H. Watarai, and T. Kurosaki. 2007. ІкB kinase $\beta$-induced phosphorylation of CARMA1 contributes to CARMA1Bcl10-MALT1 complex formation in B cells. J. Exp. Med. 204:32853293. doi:10.1084/jem.20070379

Soubeyran, P., K. Kowanetz, I. Szymkiewicz, W.Y. Langdon, and I. Dikic. 2002. Cbl-CIN85-endophilin complex mediates ligand-induced downregulation of EGF receptors. Nature. 416:183-187. doi:10.1038/ 416183a

Su, T.T., B. Guo, Y. Kawakami, K. Sommer, K. Chae, L.A. Humphries, R.M. Kato, S. Kang, L. Patrone, R. Wall, et al. 2002. PKC-beta controls I kappa $\mathrm{B}$ kinase lipid raft recruitment and activation in response to BCR signaling. Nat. Immunol. 3:780-786.

Sun, L., L. Deng, C.K. Ea, Z.P. Xia, and Z.J. Chen. 2004. The TRAF6 ubiquitin ligase and TAK1 kinase mediate IKK activation by BCL10 and MALT1 in T lymphocytes. Mol. Cell. 14:289-301. doi:10.1016/ S1097-2765(04)00236-9

Swanson, C.L., T.J. Wilson, P. Strauch, M. Colonna, R. Pelanda, and R.M. Torres. 2010. Type I IFN enhances follicular B cell contribution to the T cell-independent antibody response. J. Exp. Med. 207:1485-1500. doi:10.1084/jem.20092695

Szymkiewicz, I., K. Kowanetz, P. Soubeyran, A. Dinarina, S. Lipkowitz, and I. Dikic. 2002. CIN85 participates in Cbl-b-mediated down-regulation of receptor tyrosine kinases. J. Biol. Chem. 277:39666-39672. doi:10.1074/ jbc.M205535200

Take, H., S. Watanabe, K. Takeda, Z.X. Yu, N. Iwata, and S. Kajigaya. 2000. Cloning and characterization of a novel adaptor protein, CIN85, that interacts with c-Cbl. Biochem. Biophys. Res. Commun. 268:321-328. doi:10.1006/bbrc.2000.2147

Wang, D., R. Matsumoto, Y. You, T. Che, X.Y. Lin, S.L. Gaffen, and X. Lin. 2004. CD3/CD28 costimulation-induced NF-kappaB activation is mediated by recruitment of protein kinase C-theta, Bcl10, and IkappaB kinase beta to the immunological synapse through CARMA1. Mol. Cell. Biol. 24:164-171. doi:10.1128/MCB.24.1.164-171.2003

Watanabe, S., H. Take, K. Takeda, Z.X. Yu, N. Iwata, and S. Kajigaya. 2000. Characterization of the CIN85 adaptor protein and identification of components involved in CIN85 complexes. Biochem. Biophys. Res. Commun. 278:167-174. doi:10.1006/bbrc.2000.3760

Wen, L., J. Brill-Dashoff, S.A. Shinton, M. Asano, R.R. Hardy, and K. Hayakawa. 2005. Evidence of marginal-zone B cell-positive selection in spleen. Immunity. 23:297-308. doi:10.1016/j.immuni.2005.08.007

Wienands, J., J. Schweikert, B. Wollscheid, H. Jumaa, P.J. Nielsen, and M. Reth. 1998. SLP-65: a new signaling component in B lymphocytes which requires expression of the antigen receptor for phosphorylation. J. Exp. Med. 188:791-795. doi:10.1084/jem.188.4.791

Yamada, T., T. Kurosaki, and M. Hikida. 2008. Essential roles of mgcRacGAP in multilineage differentiation and survival of murine hematopoietic cells. Biochem. Biophys. Res. Commun. 372:941-946. doi:10.1016/ j.bbrc.2008.05.170 